\title{
Classificação Internacional de Radiografia de Pneumoconioses da International Labor Office Edição Revisada de 2000 \\ International Labor Office International Classification of Radiographs of Pneumoconioses, revised 2000 edition
}

\section{INTRODUÇÃO}

A revisão de 2000 das Diretrizes Para o Uso da Classificação Internacional de Radiografias de Pneumoconioses da $1 \mathrm{LO}$ apresenta os mesmos princípios gerais das edições anteriores (1950, 1958, 1968, 1971 e 1980), mas elucida algumas ambigüidades que vieram à luz nos últimos anos, inclusive corrigindo regras para a classificação de anormalidades pleurais.

Essas alterações são baseadas no contínuo processo de revisão, incluindo a discussão ocorrida durante a IX Conferência Internacional de Doenças Respiratórias Ocupacionais, realizada em 1997, na cidade de Kyoto, Japão.

A edição revisada de 2000 é acompanhada por dois jogos padrões: o completo (22 radiografias) e o "quadrantes" (14 radiografias). Este último inclui quadrantes de algumas radiografias do jogo completo.

\section{ALCANCE DA CLASSIFICAÇÃO}

A classificação fornece meios para se descrever e registrar sistematicamente as anormalidades que ocorrem em todos os tipos de pneumoconioses. Utiliza apenas radiografias póstero-anteriores. $\mathrm{Ou}$ tras incidências e técnicas de imagem podem ser requisitadas, porém esta Classificação não se destina ao uso dos achados nestes procedimentos.

\section{OBJETIVO DA CLASSIFICAÇÃO}

Codificar as anormalidades radiográficas das pneumoconioses de forma simples e reproduzivel. A Classificação não define entidades patológicas, não leva em conta a capacidade de trabalho, não implica em definições das pneumoconioses para fins de compensação e tampouco estabelece o nível desta compensação.

\section{USO DA CLASSIFICAÇÃO}

A Classificação é usada internacionalmente em pesquisas epidemiológicas para a seleção e supervisão de trabalhadores expostos a poeiras e para fins clínicos. 0 seu emprego permite melhor comparabilidade internacional dos achados pertinentes às pneumoconioses.

\section{RADIOGRAFIAS PADRÃO E DEFINIÇÕES}

A Classificação baseia-se no jogo de radiografias padrão e seu texto, acompanhado de uma série de notas. Essas notas foram criadas para se reduzir as ambigüidades e estão baseadas na experiência de edições anteriores. Em algumas partes do texto as radiografias padrão têm prioridade sobre a definição.

\section{INSTRUÇÕES GERAIS}

Nenhuma característica radiográfica é patognomônica de exposição a poeiras. Alguns quadros radiográficos não relacionados à exposição a poeiras podem simular pneumoconiose. Os leitores podem diferir sobre a interpretação destes achados. Os estudos epidemiológicos usualmente requerem que todos os aspectos radiográficos descritos nas diretrizes e observados nas radiografias padrão devam ser classificados. Os estudos clínicos requererem dos leitores que classifiquem somente os aspectos que acreditem ou suspeitem de ter origem pneumoconiótica. Os símbolos devem ser sempre utilizados e os comentários registrados. 


\section{INSTRUÇÕES ESPECIIFICAS PARA O USO DA CLAŚSIFICAÇÃO COMPLETA}

\section{QUALIDADE TÉCNICA}

Quanto à qualidade técnica, as radiografias são classificadas em 1,2,3 e 4. 0 exame de grau 1 é de boa qualidade, não apresentando defeitos técnicos e o de grau 4 é inaceitável, pois os defeitos técnicos impedem por completo a avaliação das anormalidades parenquimatosas e pleurais.

\section{ANORMALIDADES PARENQUIMATOSAS}

Incluem pequenas e grandes opacidades. As pequenas são descritas por:

a) Profusão de pequenas opacidades refere-se à concentração das mesmas nas zonas afetadas. A categoria da profusão é baseada em comparação com as radiografias padrão. São quatro categorias $(0,1,2,3)$ e doze subcategorias representados por:

$\begin{array}{lll}0 /- & 0 / 0 & 0 / 1 \\ 1 / 0 & 1 / 1 & 1 / 2 \\ 2 / 1 & 2 / 2 & 2 / 3 \\ 3 / 2 & 3 / 3 & 3 /+\end{array}$

Empregando-se esta escala, a radiografia é classificada primeiramente em uma das quatro categorias e a seguir na categoria acima ou abaixo considerada como alternativa (exemplo: radiografia com profusão categoria 3 , mas com categoria 2 como alternativa será considerada como $3 / 2$. Se nenhuma alternativa for observada será $3 / 3$. Subcategoria $0 / 0$ é a radiografia com ausência de pequenas opacidades ou com quantidade insuficiente das mesmas para se considerar a categoria 1 como alternativa. As radiografias padrão serão as avaliadoras finais da profusão e terão precedência sobre qualquer descrição verbal.

b) Zonas afetadas. Cada pulmão está dividido em três zonas: superior, média e inferior, por linhas traçadas em um terço e dois terços da distância vertical do ápice até a hemicúpula diafragmática.

c) Forma e tamanho. Há duas formas: regulares e irregulares. Em cada caso diferenciamos três tamanhos:

1) Regulares - Pequenas opacidades ou nódulos bem circunscritos variando até $10 \mathrm{~mm}$

$\mathrm{p}$ - opacidades com diâmetro até $1,5 \mathrm{~mm}$

q - opacidades com diâmetro entre 1,5 e 3,0 mm $r$ - opacidades com diâmetro entre 3,0 e 10,0 mm

2) Irregulares - Pequenas opacidades irregulares (lineares, reticulares ou retículo-nodulares) variando até $10 \mathrm{~mm}$

$\mathrm{s}$ - opacidades com diâmetro até $1,5 \mathrm{~mm}$

$\mathrm{t}$ - opacidades com diâmetro entre 1,5 e 3,0 mm

$\mathrm{u}$ - opacidades com diâmetro entre 3,0 e 10,0 mm

Para se registrar forma e tamanho, duas letras devem ser utilizadas. Se o leitor considerar que todas, ou virtualmente todas, as opacidades são do mesmo tamanho e forma, deve fazer o registro com letra dupla (por exemplo: q/q). Se outra forma e tamanho for observada, registra-se com a segunda letra (por exemplo: $q / t)$. lsto significa que as pequenas opacidades dominantes são regulares e de tamanho q, mas existe um número significativo de pequenas opacidades irregulares de tamanho t. Desta forma, qualquer combinação pode ser registrada.

\section{GRANDES OPACIDADES}

Este termo é usado para opacidades maiores que $10 \mathrm{~mm}$. Três categorias são definidas:

A) Uma opacidade cujo maior diâmetro tem de 10 a $50 \mathrm{~mm}$ ou diversas opacidades cuja soma de seus maiores diâmetros não ultrapassem $50 \mathrm{~mm}$;

B) Uma ou várias opacidades maiores ou mais numerosas que as da categoria A e cuja área combinada não exceda o equivalente à zona superior direita;

C) Uma ou várias opacidades cuja área combinada exceda o equivalente à zona superior direita.

\section{ANORMALIDADES PLEURAIS}

São divididas em placas pleurais (espessamento pleural localizado), obliteração do seio costofrênico e espessamento pleural difuso.

\section{PLACAS PLEURAIS}

Representam espessamento pleural localizado, geralmente da pleura parietal. Podem ser observadas no diafragma, na parede torácica (em perfil ou frontal) e em outros locais. Podem ser reconhecidas apenas por sua calcificação. São registradas como presentes ou ausentes e separadamente para os lados direito e esquerdo. Uma espessura mínima de $3 \mathrm{~mm}$ é necessária para que uma placa em perfil seja registrada. 


\section{REGIÃO}

Estão incluídos parede torácica, diafragma e outros locais (pleura mediastinal em topografia para-cardíaca ou para-vertebral). A presença ou ausência de placas é registrada em todos os locais e separadamente para os lados direito e esquerdo.

\section{CALCIFICAÇÃO}

A presença ou ausência de calcificação é registrada para todas as placas e separadamente para os lados direito e esquerdo.

\section{EXTENSÃO}

Registra-se apenas a extensão das placas ao longo da parede torácica, combinadas nas variantes em perfil e frontal:

1. comprimento total equivalente até $1 / 4$ da projeção lateral da parede lateral do tórax;

2. comprimento total entre $1 / 4$ e $1 / 2$ da projeção da parede lateral do tórax;

3. comprimento total superior a $1 / 2$ da projeção da parede lateral do tórax.

\section{OBLITERAÇÃO DO SEIO COSTOFRÊNICO}

A obliteração do seio costofrênico é registrada como ausente ou presente, separadamente para os lados direito e esquerdo. 0 limite inferior para o registro da obliteração é definido pela radiografia padrão mostrando a subcategoria $1 / 1, t / t$. Se o espessamento se prolonga até a parede lateral do tórax será registrado como espessamento pleural difuso. Obliteração do seio costofrênico pode ocorrer sem espessamento pleural difuso.

\section{ESPESSAMENTO PLEURAL DIFUSO}

0 espessamento pleural difuso somente é registrado na presença ou em continuidade com o seio costofrênico obliterado. É registrado como ausente ou presente ao longo da parede lateral e separadamente para os lados direito e esquerdo. Sua extensão é registrada da mesma maneira que a das placas pleurais.

\section{SímBOLOS}

Os símbolos são usados para se registrar aspectos radiográficos importantes e seu uso é obrigatório. Descrevem aspectos adicionais ao quadro de exposição e outras etiologias. A definição de cada um dos símbolos pode ter uma qualificação introdutória como "alterações indicativas" ou "opacidades sugestivas de" ou "suspeitas". Exemplos:

co = anormalidade do tamanho e forma cardíaca ef $=$ derrame pleural

es = calcificação em "casca de ovo" em linfonodo hilar ou mediastinal

$\mathrm{cg}=$ nódulo calcificado não pneumoconiótico 